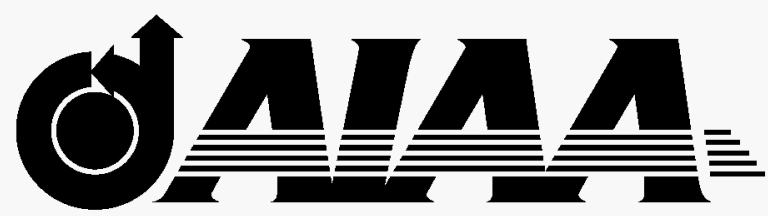

AIAA 98-4944

A Discussion of Knowledge Based Design

Richard M. Wood

and

Steven X. S. Bauer

NASA Langley Research Center

Hampton, Virginia

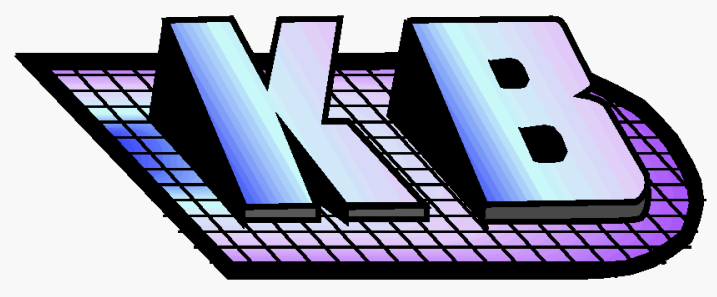

7th AIAA/USAF/NASA/ISSMO Symposium on Multidisciplinary Analysis and Optimization September 2-4, 1998 / St. Louis, MO

For permission to copy or republish, contact the American Institute of Aeronautics and Astronautics 1801 Alexander Bell Drive, Suite 500, Reston, VA 20191-4344 


\title{
A Discussion of Knowledge Based Design
}

\author{
Richard M. Wood ${ }^{*}$ and Steven X. S. Bauer ${ }^{\dagger}$ \\ NASA Langley Research Center \\ Hampton, Virginia
}

\begin{abstract}
$\underline{\text { ABSTRACT }}$
A discussion of knowledge and KnowledgeBased design as related to the design of aircraft is presented. The paper discusses the perceived problem with existing design studies and introduces the concepts of design and knowledge for a KnowledgeBased design system. A review of several Knowledge-Based design activities is provided. A Virtual Reality, Knowledge-Based system is proposed and reviewed. The feasibility of Virtual Reality to improve the efficiency and effectiveness of aerodynamic and multidisciplinary design, evaluation, and analysis of aircraft through the coupling of virtual reality technology and a Knowledge-Based design system is also reviewed. The final section of the paper discusses future directions for design and the role of Knowledge-Based design.
\end{abstract}

\section{$\underline{\text { INTRODUCTION }}$}

A review of the literature on design shows a wide diversity of methods, concepts, and ideas being investigated and developed ${ }^{1-22}$. In general, these concepts fall into two groups, those that are Computationally-Based (CB) Design such as MultiDisciplinary Optimization ${ }^{16}$ and those that are Knowledge-Based (KB) Design such as DecisionBased Design ${ }^{22}$. The primary assumption of $\mathrm{CB}$ Design is that a design process can be modeled in the computer to allow the computer to find the optimum design more efficiently than a human. CB Design systems are processes that are used to generate

*Senior Research Aerodynamicist, Licensed Professional Engineer, Senior Member AIAA

†Aerospace Engineer, Configuration Aerodynamics Branch, Senior Member AIAA

Copyright (C) 1998 by the American Institute of Aeronautics and Astronautics, Inc. No copyright is asserted in the United States under Title 17, U.S. Code. The U.S. Government has a royalty-free license to exercise all rights under the copyright claimed herein for government purposes. All other rights are reserved by the copyright owner. designs. Another assumption behind the CB Design is based upon the use of explicit and critical knowledge only and does not recognize the role of tacit and intuitive knowledge and other human senses and capabilities in the design process.

At the other end of the design environment are KB Design systems in which it is recognized that all knowledge as well as passion is required to find the best design. KB Design systems consist of tools that allow a designer to utilize their skills, senses, and knowledge in pursuit of a desired outcome. KB Design should not be confused with Artificial Intelligence (AI) or Expert Systems (ES) because those systems assume that the human knowledge and decisions can be fully modeled into a process and computerized. It is important to note that this is clearly not the case because we do not know the extent of our knowledge.

A review of the aircraft design environment shows that the ability to perform efficient and effective aerodynamic and multidisciplinary design is quickly becoming a lost skill. A significant portion of this problem has resulted from the increased reliance by the aeronautics community upon computational tools for both aerodynamic analysis and design ${ }^{15,16}$. This trend towards Computational Based (CB) design and decision making also dominates the multi-disciplinary design environment. As this trend continues, the knowledge and skills, which are the critical elements in the design practices, will slowly erode as the computational tools replace the need for human interaction. This trend will eventually result in a stagnant design technology landscape. While many still believe that computational design is the pathway to improved efficiency and effectiveness in the design environment others are starting to question the reliance upon computational tools. A significant portion of the design community believes that it is critical to maintain human involvement and learning in the design and analysis process ${ }^{17-22}$. This gives rise to the use of KB systems which model the aircraft design knowledge as a continuous landscape. The amount of information and data to be converted to knowledge to 
launch such a system is extremely large. Such a proposed system would require the evaluation, analysis, and interaction with significant amounts of additional information. This requirement can become an insurmountable task if traditional data display and manipulation media are used. However, it is expected that Knowledge Management Systems ${ }^{5,7}$, Virtual Reality (VR) technology $y^{23-30}$, and other advanced information management and display technologies may offer the opportunity for KB design systems to reach their full potential.

The purpose of this paper is to have a discussion of knowledge and $\mathrm{KB}$ design as related to the design of aircraft in an effort to provide an alternative to $\mathrm{CB}$ design. The paper will first discuss the perceived problem and the concepts of design and knowledge. A discussion of $\mathrm{KB}$ design and a review of several examples will follow. The final section of the paper will discuss future directions for design and the role of KB design. A Virtual Reality, Knowledge Based (VR KB) system will be proposed and reviewed. The feasibility of Virtual Reality (VR) to improve the efficiency and effectiveness of aerodynamic and multidisciplinary design, evaluation, and analysis of aircraft through the coupling of virtual reality technology and a $\mathrm{KB}$ design system will also be addressed.

\section{PROBLEM AND SOLUTION PATHWAY}

\section{$\underline{\text { Problem }}$}

The engineering design problems are many and diverse. They range from definitions to philosophy to our focus. Perhaps the number one issue is the failure of the engineering community to recognize that a designer is a unique and highly skilled individual and that only a designer can create. In our present environment, it appears as if everyone either wants to design or they want to control the design process, however, there is a severe shortage of designers. The distinction between a designer and a person doing design work is equivalent to the difference between a world-renowned violinist and a person playing a $\mathrm{CD}$ of their music. The first uses extreme intellect, knowledge, and passion to create and the latter executes a routine process that recreates.

Another area of concern is the lack of focus and resulting fragmentation of the design efforts. A quick review of the literature revealed a large number of design system types ${ }^{1-22}$, a few are shown in table 1 .
However, there does not appear to be any organization, categorization, or classification of these systems. In addition, there are many different submethods and systems that are listed under each of the systems listed in table 1 . This diversity in work inhibits the focusing of resources to develop the necessary skills, capabilities, and tools to support the design needs of the future.

\begin{tabular}{|l|}
\hline \multicolumn{1}{|c|}{ TABLE 1. } \\
\hline Artificial Intelligence \\
\hline Case Based Design \\
\hline Computer Aided Design \\
\hline Concurrent Design \\
\hline Decision Based Design \\
\hline Design of Experiments \\
\hline Design Synthesis \\
\hline Design to Cost \\
\hline Expert Systems \\
\hline Integrated Design \\
\hline Knowledge Based Design \\
\hline Multi-Disciplinary Analysis and \\
Optimization \\
\hline Multi-Disciplinary Design \\
\hline Multi-Disciplinary Optimization \\
\hline Pattern Recognition Design \\
\hline
\end{tabular}

Table 1. Design System Types

The present focus in design is faster, faster, faster and cheaper, cheaper, cheaper ${ }^{15,16}$. This trend has resulted in cost concerns replacing creativity, innovation, and performance. The primary means to achieving the cost reduction goal has been through the use of computer modeling of design processes ${ }^{23}$. While computers are a critical tool to the engineering design community, it is a critical mistake to view them as the heart and soul of design. In the quest to be viewed as on the forefront of technology, there is a mad rush to automate processes, and computerize the capabilities and skills of engineers ${ }^{1,2,9}$. In developing this model of engineering capabilities, a select few have had to define the minimal set of critical data, information, and knowledge and treat the remaining knowledge and capabilities as a disposable commodity. A result of the computerization of the engineering discipline is the disregard for intuitive 
data, information, and knowledge. This trend will result in the creative and innovative practices of the past being replaced with routine processes. Another byproduct of this trend is that there will be a severe lack of understanding of final design performance; this will result in costly redesign during the development and production activities.

The final issue is related to the designdevelopment time line as shown in figure 1. The figure shows that the opportunities to impact performance or cost of a design are heavily weighted toward the conceptual design phase where the design activity is typically guided by first order effects and simple models ${ }^{10,16,17}$. Only a fraction of the available knowledge for the particular design problem is associated with these methods and models. This inverse relationship between knowledge used and design impact must be corrected if significant improvements are to be achieved.

\section{Solution Pathways}

The proposed solution pathway leads through Conceptual Design and KB Design in three steps. The first step is to recognize that the Conceptual Design phase must be a highly creative, multidisciplinary activity in order to minimize cost and maximize design performance. Second, the Conceptual Design phase must be re-created into a $\mathrm{KB}$ Design activity that is without intellectual restraint. And the third step is the recognition that designers and not the design process are the critical element in design ${ }^{17}$. These ideas are graphically depicted in figure 2 in which Performance and Cost curves as well as Available Knowledge curves for the existing design processes and the proposed $\mathrm{KB}$ design practices are shown. By inserting more knowledge into the Conceptual Design phase, greater cost and performance benefits will be achieved. As a result, we achieve a better, faster, and cheaper design.

The remaining issue is whether $\mathrm{KB}$ or $\mathrm{CB}$ systems are more effective and efficient in integrating knowledge into a design. The argument in support of the KB system is graphically depicted in figure 3 in which the trend in cost against knowledge complexity is presented for both a $\mathrm{KB}$ and $\mathrm{CB}$ system. The figure shows that the cost for minimal knowledge is similar for both a $\mathrm{KB}$ and $\mathrm{CB}$ system, however, as knowledge complexity increases, the $\mathrm{CB}$ cost increases dramatically due to computational modeling, solution generation, and solution interrogation ${ }^{31}$. A much different trend is observed for a KB system.
The figure shows that a $\mathrm{KB}$ system requires minimal additional increases in cost for adding knowledge, once the system is established.

\section{WHAT ARE DESIGN AND KNOWLEDGE?}

Now that you are fully confused, violently disagree, or perhaps violently agree with the previous statements, a few points will be clarified by providing some definitions of design, knowledge and their associated terms.

\section{Design}

Each person is actively designing throughout his or her life. We design our day, our drive to work, our meals and our conversations. We design organizations, toasters, art, and airplanes. Designing is thinking, feeling, and knowing. However, to design an optimum "thing" requires a cognitive awareness of all knowledge relative to a desire. This is clearly not achievable by man or possible by computer. It is also clear that a designer is different from one who designs. In an attempt to clarify these points, the following terms must be defined:

A Design is a concept, model, or artifact with desired performance.

A Designer is a passionate and knowledgeable decision-maker that utilizes critical and intuitive skills.

Designing is a creative practice that stimulates and liberates and is learned through the acquisition of knowledge.

Knowledge

You do not know what you know, however, it is possible to use all that you know in the design process. To know that you do not know what you know is the first step in becoming a successful designer. This knowledge allows you to accept your intuition (i.e., gut feeling) as useful knowledge and as an integrator of knowledge.

It is important to use all of one's knowledge whether or not it relates directly to design. Therefore, thoughts derived as a child affect how one thinks and the decisions one makes as an adult. An example of a thought-provoking book relative to this subject is Dr. Seuss' "Oh, the THiNKS you can ThinK!"32. 
Ted Geissel eloquently illustrates how anything is possible.

To define knowledge, as related to engineering, you must also define data and information. The following definitions are provided:

Data a group of facts or statistics that have not been assigned meaning.

Information data that has been assigned meaning.

Knowledge the sum of what has been perceived and learned that allows for the generation of information.

A graphical depiction of the interrelation between data, information, and knowledge is presented in figure 4 . The figure shows that data is operated on by knowledge to produce information and a new set of knowledge. The new knowledge is combined with information to create knowledge. This knowledge set is then used in the interaction with new data and information sets.

Another important aspect of knowledge creation is the four modes of knowledge creation introduced by Nonaka ${ }^{5}$ in 1995 , see figure 5 . In this model, there are two basic types of knowledge, tacit and explicit. Nonaka states that knowledge is created by the conversion of tacit to both tacit and explicit and from explicit to both tacit and explicit. Relating these thoughts to the $\mathrm{CB}$ and $\mathrm{KB}$ design systems, we see that $C B$ makes use of only two modes: tacit to explicit and explicit to explicit knowledge steps whereas $\mathrm{KB}$ uses all four modes.

The final knowledge concept is the notion of a "Knowledge Matrix"(see figure 6) which is borrowed from the work of Margolis ${ }^{7,33}$ in 1987 on a cognitive model he termed the "Belief Matrix". Margolis states that there is tension between critical and intuitive scrutiny to a question and the yes $(+)$, no $(-)$, and maybe (o) answers to the critical and intuitive question form nine affective states. In his model, a yes answer $(+)$ to both the critical and intuitive questions is the knowledge affective state, upper left corner of matrix. For this discussion, the nine affective states of Margolis have been renamed to reflect levels of knowledge awareness. In the "Knowledge Matrix", there are four levels of knowledge awareness; Known Knowledge, Unknown Knowledge, Probable Knowledge, and Possible Knowledge. These states reflect the concept that "all" that is possible to be known can be known. The important design aspect of this concept is that in typical design systems only the $\mathrm{C}+/ \mathrm{I}+$ Known Knowledge state is utilized. However, in some design systems, all of the $\mathrm{C}+$ states are used due to a blind reliance on computational results. The benefit of a KB system is that all nine states are used.

\section{KNOWLEDGE-BASED DESIGN}

KB Design has been discussed within the literature in the context of Artificial Intelligence (AI) and Expert Systems (ES) but not in the context of designer driven practices within a broad $\mathrm{KB}$ design space. The KB design system that is the topic of this paper is one that is practiced by a designer who relies upon intellectual optimization and thought experiments in developing a particular solution pathway. The designer respects simplicity, recognizes that nature and its laws are continuous, and understands that rebellion and debate are necessary tools. Another description that reflects this view is that expressed by Alexander H. Slocum ${ }^{13}$ in his position paper for the Decision-Based Design Workshop located at:

www.eng.buffalo.edu/Research/DBD/

"Designers have a bio-neural-net programmed for deterministic axiomatic thought while simultaneously achieving rapid-fire multitechno happiness enhancement"

"Designers need tools that catalyze their thoughts....and harness an attribute that no neural net can dream of, a passionate lust to create a most awesome amazing orgasmic design."

\section{Designer's Practice}

The designer begins the design challenge by taking an infinite view of the problem. This first step is critical and may be viewed as designing the design. Designing the design provides context and content but does constrain or inhibit. This perspective is shown in the model of the design space shown in figure 7. The design space model shown has six regions depicted as successively smaller regions. This representation is consistent with the present design process. However, for a $\mathrm{KB}$ design system, this is only true for Possibility, Probability, Knowledge, and Known Knowledge spaces. For KB design, the $\mathrm{Cb}$ and $\mathrm{Tb}$ design spaces are not scaled and are not assumed to reside within the $\mathrm{K}^{2} \mathrm{~b}$ design space 
but are characterized as concept families. Another point to note is that the Constraint and Tool spaces are scaled by various factors such as politics, resources, and culture. In addition, the relative size of the Constraint and Tool spaces may reverse from that shown and they may extend outside of the $\mathrm{K}^{2}$ into the $\mathrm{K}, \mathrm{Pr}$, and Po spaces. The goal in the practice of $\mathrm{KB}$ design is to utilize tools and constraints as influence factors in order to use as much of the design space as possible.

The next issue faced by the designer is the dilemma between using a "Design Process" or "Design Practice" as shown in figure 8. As one would expect, the designer prefers the Design Practice as depicted on the right side of figure 8 . However, politics, resources, and culture attempt to drive the designer to a process as shown on the left. The major differences between the two are that the Process is an inside-out activity, which knowingly utilizes only a small section of the design space, whereas the Practice is an outside-in activity, which utilizes the full design space. The Process represents the scale factors (Xbsf's), constraints, and tools as hard models where the Practice recognizes and conceptualizes the existence of these desires and chooses the degree of acceptance.

The final challenge the designer faces is the work environment or team structure. As depicted in figure 9, there are three types of teams that are possible; Bureaucratic, Hierarchical, and Creative. The Bureaucratic team is formed by the organization and exists as an element of the organization. This team is recognized as being in competition with other elements of the organization and must operate within the organizational policies and culture. The Hierarchical team is formed by the participating elements of the organization to perform a task of mutual benefit. This team is supported as long as it is recognized as adding value to the individual elements of the organization. Those who have a shared passion and are committed to achieving success form the Creative team. The Creative team operates within the organization environment but not for the organization. The preferred team is the Creative team, however, it is not one that is typically supported by an organization. The characteristics of a Creative team are increased communications, productivity, and reduced complexity and cost compared to the other two teams.

The ability to create the preferred designers environment requires the recognition that knowledge is the most valued commodity and that creativity and innovation are critical. If these three characteristics are present then a KB system can achieve success.

The next three sections of the paper will review the results of three activities from 1985, 1990, and 1995 that used $\mathrm{KB}$ design in a creative team environment.

\section{Natural Flow Wing (NFW) Design}

The Natural Flow Wing ${ }^{34}$ (NFW) Design activity took place in 1985 with a team of four engineers representing the disciplines of aerodynamics, structures, survivability, and manufacturing maintainability. The design activity focused on the development of $\mathrm{KB}$ design rationale for including nonlinear effects into the conceptual design phase of the multidisciplinary design of highly efficient multi-point-design wings. The design approach was derived from experimental observations and an extensive parametric computational study. The proposed design rationale is based on criteria from the following disciplines; aerodynamics, structures, survivability, and manufacturing/ maintainability. The combination of criteria for these disciplines indicates that the optimum wing would be a symmetric, planar geometry without breaks to the outer mold line.

The first step in the design is to develop an understanding of the various layers to the design space presented in figure 7. A description of each of these design space layers is presented in figure 10. The vision of the Possibility-based (Pob) design space is characterized by all 3-D shapes with smooth and continuous geometry. The recognition of the need for 3-D geometry is related to the volumetric and structural requirements of the design and the need for smooth and continuous geometry addressing aerodynamics and survivability considerations.

The second layer is the Probability-based (Prb) design space. Within this space, we add to the Pob design space description by calling for a benign pressure loading and an aerodynamic insensitivity to volume. These two additional descriptors characterize the expected aerodynamic performance of the design and provide a vision of a design with a very robust performance map.

A review of the descriptors for the Knowledge-based $(\mathrm{Kb})$ design space shows that low drag, no movement of the aerodynamic center, and 
increased volume are added to the Prb design space characteristics. These new characteristics add to the vision that the final design will be very robust and have excellent aerodynamic characteristics.

The next design space is the Known Knowledge-based $\left(\mathrm{K}^{2} \mathrm{~b}\right)$ design space where design guidance is provided. For this design space, the intent is to take advantage of experimental and computational data observations of 3-D pressure loadings over similar planforms and then to use these contours as maps to guide the reshaping of the wing geometry to match the observed 3-D pressure loading.

The final two elements are the Constraint based $(\mathrm{Cb})$ and Tool based $(\mathrm{Tb})$ design spaces. For a traditional design, the $\mathrm{Cb}$ and $\mathrm{Tb}$ design spaces are assumed to reside within the $\mathrm{K}^{2} \mathrm{~b}$ design space and are sized according to non-technical factors such as politics, culture and resources. However, for $\mathrm{KB}$ design, the $\mathrm{Cb}$ and $\mathrm{Tb}$ design spaces are not scaled and are not assumed to reside within the $\mathrm{K}^{2} \mathrm{~b}$ design space but are characterized as concept families that are used to guide the design. For this design, the $\mathrm{Cb}$ design space description is that the volume will be sufficient to fly a candidate mission and the $\mathrm{Tb}$ design space will have an analytic geometry definition capability.

With the Pob through Tb design spaces thoughts and visions in hand, a design activity is initiated and managed by the designer. The resultant design is depicted in figure 11. Shown on the left of the figure are sketches of the NFW design and a traditional design. Note that the NFW design is flat and planar where the traditional design is characterized by having camber and twist. This geometric characteristic is critical in satisfying the survivability requirement. Another characteristic of the design is the increased volume for the NFW design over the traditional design. The resulting performance is shown on the right on the figure in the form of a drag polar. The NFW design had lower drag at all lift coefficients than the traditional design. These results indicate that the NFW design achieved all of the stated objectives and produced a new aerodynamic shape family that provides unique aerodynamic and survivability performance.

\section{Advanced Aircraft Control Effector (AACE) Design}

The Advanced Aircraft Control Effector (AACE) Design activity was conducted in 1990 with a team of 11 engineers representing aerodynamics, electromagnetics, controls, structures, propulsion, and weights. AACE focused on the design of advanced aircraft control effectors that allow for the development of low drag, highly agile aircraft that are affordable and satisfy future observability requirements. In pursuit of this goal, it was recognized that several new concepts would be required that were passive devices or micro in size. Another concept introduced was the notion of designing the planform as a zero-order control effector and to actuate the planform through the use of micro motion boundary layer control devices.

As was done in the NFW design activity discussed previously, the first step in the AACE design was to develop an understanding of the design space. The list of characteristics for each of the 6 design space layers is shown in figure 12. A review of these descriptions shows that the design spaces are notionally described and each successive design space builds upon the description of the previous space. Another characteristics of KB design is the use of very aggressive performance objectives as shown in figure 12. An interesting point for this design is the absence of any significant Constraint or Tool based description. The $\mathrm{Cb}$ and $\mathrm{Tb}$ design space for the AACE activity must have infinite freedom to allow the creation of new technologies and concepts, that are required to meet such severe performance objectives.

Presented in figure 13 are the resultant technologies developed and performance benefits achieved in the AACE design. A graphic of the AACE design concept is also shown in the figure. The AACE activity produced a large number of new technologies of which five are patent pending. These technologies ranged from advanced planform concepts to micro boundary layer control devices. The success of these devices in achieving the stated goal is itemized in the table on the right side of figure 13. The AACE activity produced large aerodynamic, electromagnetic, control, and weight benefits as indicated. These results indicate that the AACE activity was successful and delivered new design technologies and a new design philosophy to the community.

\section{High Speed Research (HSR) Arrow-Wing Design}

The High-Speed Research (HSR) Arrow Wing Design activity was conducted in 1995 with a team of 6 engineers representing the disciplines of aerodynamics, structures, propulsion, controls, and weights. This design activity was the first attempt to 
apply the military based NFW design philosophy to a commercial design problem. The focus of this effort was a numerically-optimized, Euler- (and NavierStokes) based arrow wing design within the HSR program. The focus of the design was to reduce the supersonic and transonic drag while increasing volume. It was expected that the NFW design approach would produce the characteristic flat wing and eliminate much of the waviness characteristic of the conventionally optimized designs.

As with the two previous examples, the first step in the design was to characterize the design space. It should be noted for this design, the HSR program had very strict constraints and requirements on volume, thickness, spar thickness and location, leading-edge radius, fuselage incidence, engine location and orientation, etc. However, the KB design activity did not hold these as rigid values as was done by other HSR design teams. This design study recognized the HSR constraints as desired outcomes ONLY. As a result, a review of the design space model for this activity show the same characteristics as those for the NFW design activity on figure 10 , see figure 14 .

Presented in figure 15 are the results of this design. Depicted at the top of the figure is a sketch of the wing main structural element and on the right are sketches of the airfoil sections for the conventionally optimized wing (CB) and NFW wing (KB). These sketches show how the NFW design has greater volume than the CB-optimized wing. Also note that the NFW included multidisciplinary effects by reshaping the structural box. A comparison of the performance of the two designs show that the NFW has three counts lower drag at the cruise point and has an increase of nearly $5 \%$ in useable volume. As with the two previous examples, these results clearly show that this KB design activity was successful in achieving its goal.

A review of the three examples shows the benefit of relaxing constraints and allowing creativity to have a role. The $\mathrm{KB}$ design process allows the designer to produce outstanding results with minimal resources. Each of the designs shown above was completed ahead of schedule and under budget. In addition, each of the design activities created new technologies that remain in use today.

\section{FUTURE DIRECTIONS}

The previous sections of the paper have addressed the general problem of design and have reviewed some aircraft design studies in the context of $\mathrm{KB}$ design. This section of the paper will provide an aerodynamicists view towards design and discuss some specific problems in aircraft design and propose a solution to these problems.

Over the past decade, there has been uncontrolled growth in the use of computers in the design of aircraft, consequently, there also appears to have been an equally dramatic uncontrolled reduction and shift in knowledge related to aircraft design. If this trend continues, the ability to use aircraft design tools would only require a limited understanding of aircraft design and aerodynamics and as a result we would approach Dr. Doug Dwoyer's 1987 prediction $^{35}$, "If you ask me to envision what I see in the year 2020, there will be no wind tunnels. I would say we would be at the point where airplanes could be designed by rather low-paid technicians."

At this time, the aircraft design environment has become intellectually stagnant and is focused only on computational efficiency. And within this design environment, the Aerodynamicist has become an observer unable to contribute to our design intellect and knowledge. It is clear from all points that we are losing large amounts of design potential by not including knowledge of nonlinear effects into the conceptual design activity. Our next generation of design methods must have the ability to capture and share knowledge. These new methods must support the creative and innovative activities of designers. And lastly we must not be constrained by existing performance boundaries.

To satisfy these needs, it is proposed that $\mathrm{KB}$ design tools and design practices be created that provide the framework for designers to reduce the design cycle time an order of magnitude and to achieve performance goals that exceed recognized boundaries by $50 \%$. This new system could require Virtual Reality (VR) coupled with a KB system. A schematic of a proposed VR KB system is depicted in figure 16 . The proposed system would utilize the VR technology as a means to increase the efficiency of the KB design system. The VR shell will create a designer-friendly work environment where knowledge and a design can be accessed in real time and integrated in real time to create a new design. A critical element of the KB system is an unrestricted 
ability to create a smooth geometry of any concept or notion. Residing under the geometry shell are the synthesis tools that manage the existing knowledge as well as capture the new knowledge generated within the system. A critical element of this system is the efficient modeling of the information and knowledge domains, which would allow for effective transformation and morphing of these domains between problem sets.

The most important characteristic of a $\mathrm{KB}$ system is that it must be a learning system. This characteristic is depicted in figure 17 which shows the design cycle for a $\mathrm{KB}$ system. A design activity would start with a definition of the design space and the design goal. The generation or the importing of a description (geometry model) of the concept would follow. The designer would then interrogate the Knowledge Domain (KD) relative to the model and stated goal. If the $\mathrm{KD}$ is valid for this problem, the relative information is extracted and the results are synthesized into a possible solution and the process is repeated until the designer is satisfied. If the $\mathrm{KD}$ is not valid, there are two steps taken; the first is to characterize the $\mathrm{KD}$ relative to the problem and update the $\mathrm{KD}$, the second option is to review the Information Domain (ID). A review of the ID takes the same form as the KD with the exception that if the ID is not valid, the resolution is to obtain new data to feed the ID and KD models shown in figure 18 and 19. It is important to note that without the learning capability of the proposed system knowledge would be lost and we would spend more time and resources re-creating than creating. Note the KB system utilizes both knowledge-based models and information based models as shown in figures 18 and 19. The transformation of data to information to knowledge is critical for the system to learn.

\section{CONCLUDING REMARKS}

Design is a greatly misunderstood and undervalued practice within the engineering community. This is especially true for $\mathrm{KB}$ systems despite the fact that each of us actively practice $\mathrm{KB}$ design in our everyday lives. When we arrive at work, we become "Dilbertized" ${ }^{\text {"36 }}$ by our environment and fall into the daily process-management routine of re-creating knowledge. These random process acts must be restructured into creative and innovative practices using KB systems if we are to move technology forward.
Relative to aircraft design; it is important to recognize that the design philosophy, not the design process, defines the design space. The design philosophy, which is developed by the designer, must not be constrained by known rules, constraints, or by computational tools. It is also extremely important to recognize that the ability to perform conceptual nonlinear design is not contingent upon the ability to obtain a computational solution. The efficiency and accuracy of the conceptual design phase is directly related to the knowledge used, thus we must focus on including ever greater amounts of knowledge into the conceptual design phase.

To address the need for improved design capability, the following recommendations are offered:

- Establish a National Design Consortium to facilitate the development of design knowledge, design skills, and design systems.

- Accelerate the development of learning, knowledgemanagement systems for designers

- Accelerate the development of advanced display, information management, and virtual reality technologies.

- Recognize that design is a knowledge driven activity, not a computational process.

\section{REFERENCES}

1. Liebowitz, J.: An Introduction to Expert Systems. Mitchell Publishing, Inc., 1988.

2. Liebowitz, J.: The Handbook of Applied Expert Systems. CRC Press, 1998.

3. Ferguson, E. S.: Engineering and the Minds Eye.. MIT Press, 1992

4. Suh, N. P.: The Principles of Design. Oxford University Press, 1990.

5. Nonaka, I. And Takeuchi, H.: The Knowledge Creating Company. Oxford University Press, 1995.

6. Robinson, A. G. and Stern, S.: Corporate Creativity, How Innovation and Improvement Actually Happen. Berrett-Koehler Publishers, Inc., 1997.

7. Liebowitz, J. and Wilcox, L. C.: Knowledge Management and Its Integrative Elements. CRC Press, 1997. 
8. Carr, C.: The Competitive Power of Constant Creativity. AMACOM, 1997.

9. Kidwell, G. H.: The Workshop on AI Applications to Conceptual Aircraft Design. NASA TM-105445. 1990.

10. Gonda, M., Fertig, K. W., and Teeter, R. J.: Aerospace Conceptual Vehicle Design Using an Intelligent Design and Analysis Environment: Design Sheet. AIAA92-4222. August 1992.

11. Papamichael, K. and Protzen,J-P: The Limits of Intelligence in Design. LBL-31742. 4th International Symposium on System Research, Informatics and Cybernetics. August 1993.

12. AGARD. Integrated Airframe Design Technology. AGARD-R-814. October 1996.

13. Slocum, A. H.: Passionate Axiomatic Deterministic Design: A Plea for the Future of Designology. Decision Based Design Workshop located at www.eng.buffalo.edu/Research/DBD/

14. Olds, J. R.: Multidisciplinary Design Techniques Applied to Conceptual Aerospace Vehicle Design. NASA CR- 194409. 1993.

15. Newman, P. A., Hou, G.J.-W. and Taylor III, A. C.: Observations Regarding Use of Advanced CFD Analysis, Sensitivity Analysis, and Design Codes in MDO. NASA CR-198293, March 1996.

16. Kroo, I., Altus, S., Braun, R., Gage, P. and Sobieski, I.: Multidisciplinary Optimization Methods for Aircraft Preliminary Design. Fifth AIAA/USAF/NASA/ISSMO Symposium on Multidisciplinary Analysis and Optimization. AIAA 94-4325. September 1994.

17. Meyer, D. D.: Future Integrated Design Process. NASA CP-2143. 1980.

18. Null, C. H. and Jenkins, J. P.: NASA Virtual Environment Research, Applications and Technology. NASA TM-109682. October 1993.

19. French, M. J.: Conceptual Design for Engineers. The Design Council, 1985.

20. Newsome, S. L., Spillers, W. R. and Finger, S.: Design Theory'88. Springer-Verlag, 1988.

21. Gero, J. S.: Design Optimization. Volume 1. Academic Press, 1985.
22. Decision Based Design Workshop located at www.eng.buffalo.edu/Research/DBD/

23. Bryson, S.: Paradigms for the Shaping of Surfaces in a Virtual Environment. RNR-92-012

24. Brooks, F. P., Jr. and Fuchs, H.: Advanced Technology for Portable Personal Visualization. AD-A261 294. 1993.

25. Dodd, G. G.: Virtual Reality for Automotive Design Evaluation. NASA CP-3320. November 1995.

26. Montoya, R. J.: Applied Virtual Reality at the Research Triangle Institute. NASA CP-10163. November 1994.

27. Hale, J. P.: Applied Virtual Reality in Aerospace Design. NASA TM-110737. January 1995.

28. Motiwalla, J. and Feiner, S.: Virtual Reality Software and Technology '94. AGARD-TR-9430. August 1994.

29. Edwards, D. E.: Scientific Visualization Current Trends and Future Directions. AIAA 920068. January 1992.

30. Grimsdale, C.: Virtual Reality Evolution or Revolution. AGARD Virtual Interfaces: Research and Applications. May 1994.

31. Bailey, F. R. and Simon, H. D.: Future Directions in Computing and CFD. RNR-92019. May 1992.

32. Geissel, T.: Oh, the THiNKS you Can Think! Beginner Books, A Division of Random House, Inc. 1975 .

33. Margolis, H.: Patterns, Thinking, and Cognition: A Theory of Judgement. Chicago: The University Press, 1987.

34. Wood, R. M. and Bauer, S. X. S.: The Natural Flow Wing-Design Concept. NASA TP 3193 , May 1992.

35. Mayfield, D.: Turning Flights of Fancy into Reality. The Virginia Pilot and Ledger Star, Hampton Roads Business Weekly. Pg. 16-17. February 2, 1987.

36. Adams, S.: "The Dilbert Principle", Harper Business, A Division of Harper Collins Publishers. 1996. 


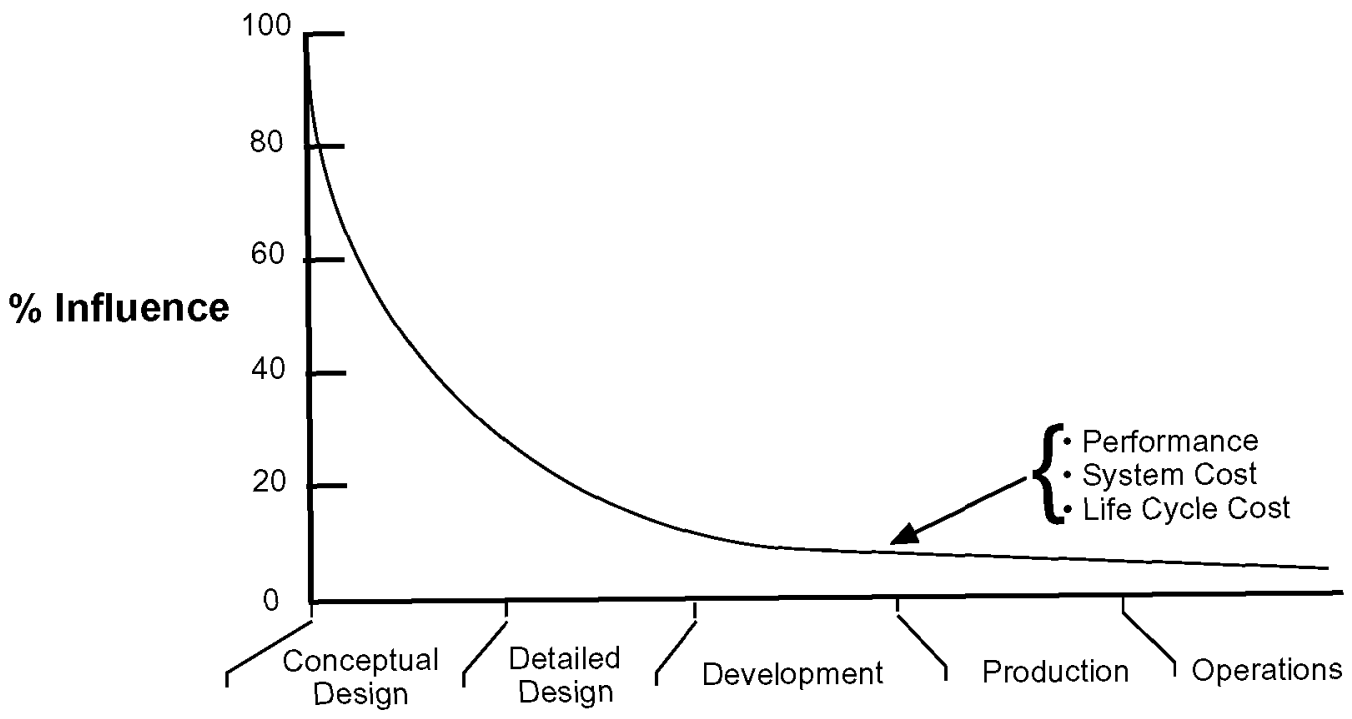

Time Line

Figure 1. Graph showing the change in design influence on performance and cost with time.

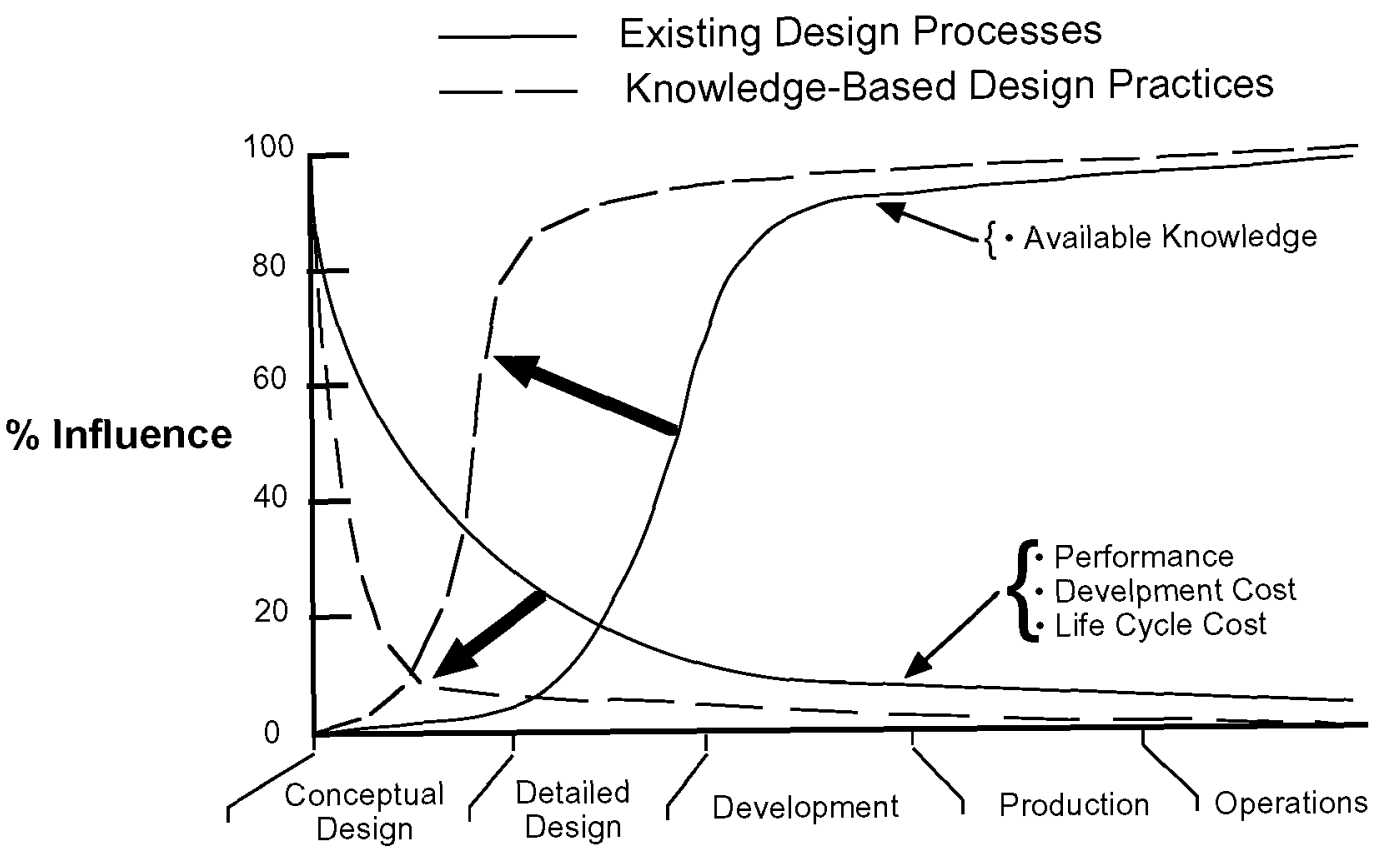

Time Line

Figure 2. Graph showing the impact of knowledge on performance and cost in design. 


\section{Computational-Based (CB) Design Processes}

- Knowledge-Based (KB) Design Practices

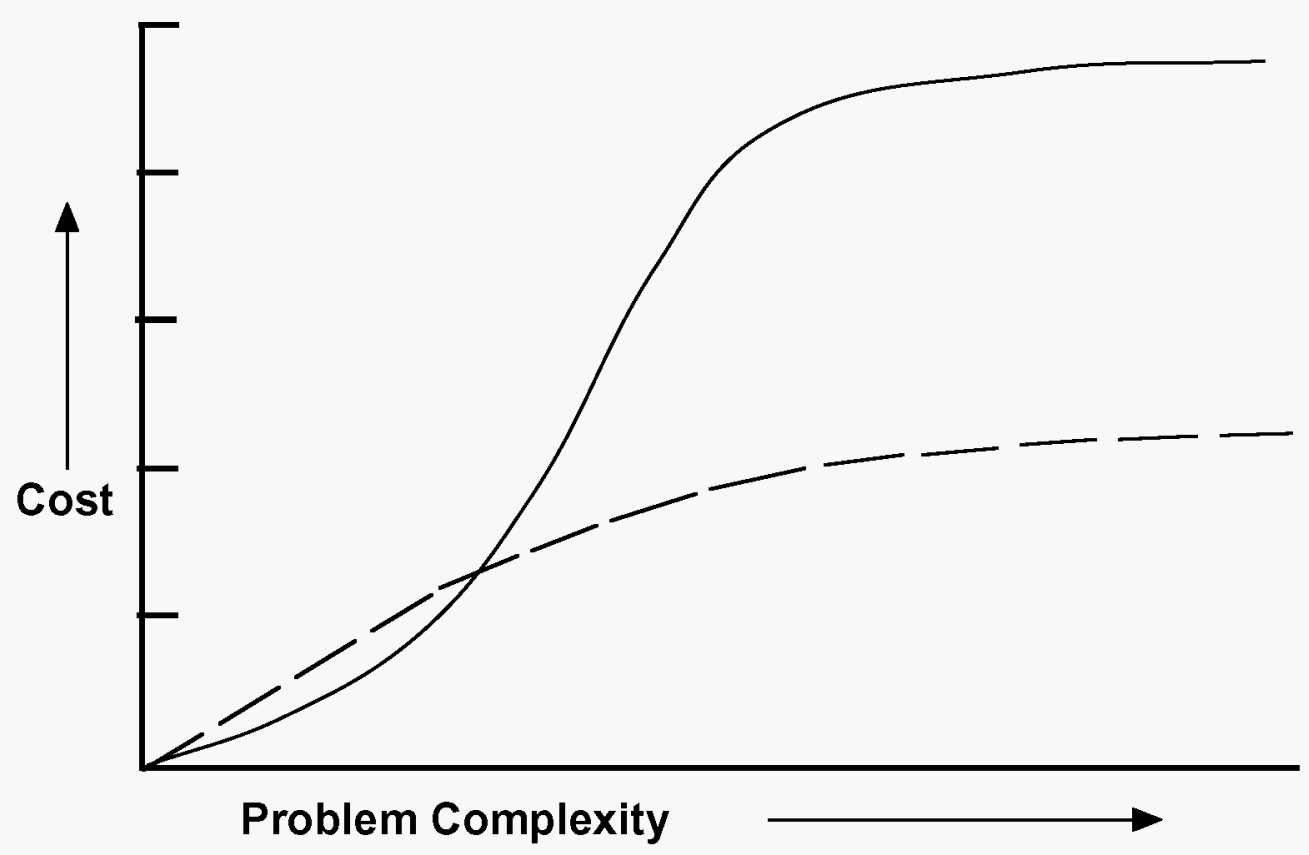

Figure 3. Graph comparing the cost of knowledge for $\mathrm{CB}$ and $\mathrm{KB}$ design systems.

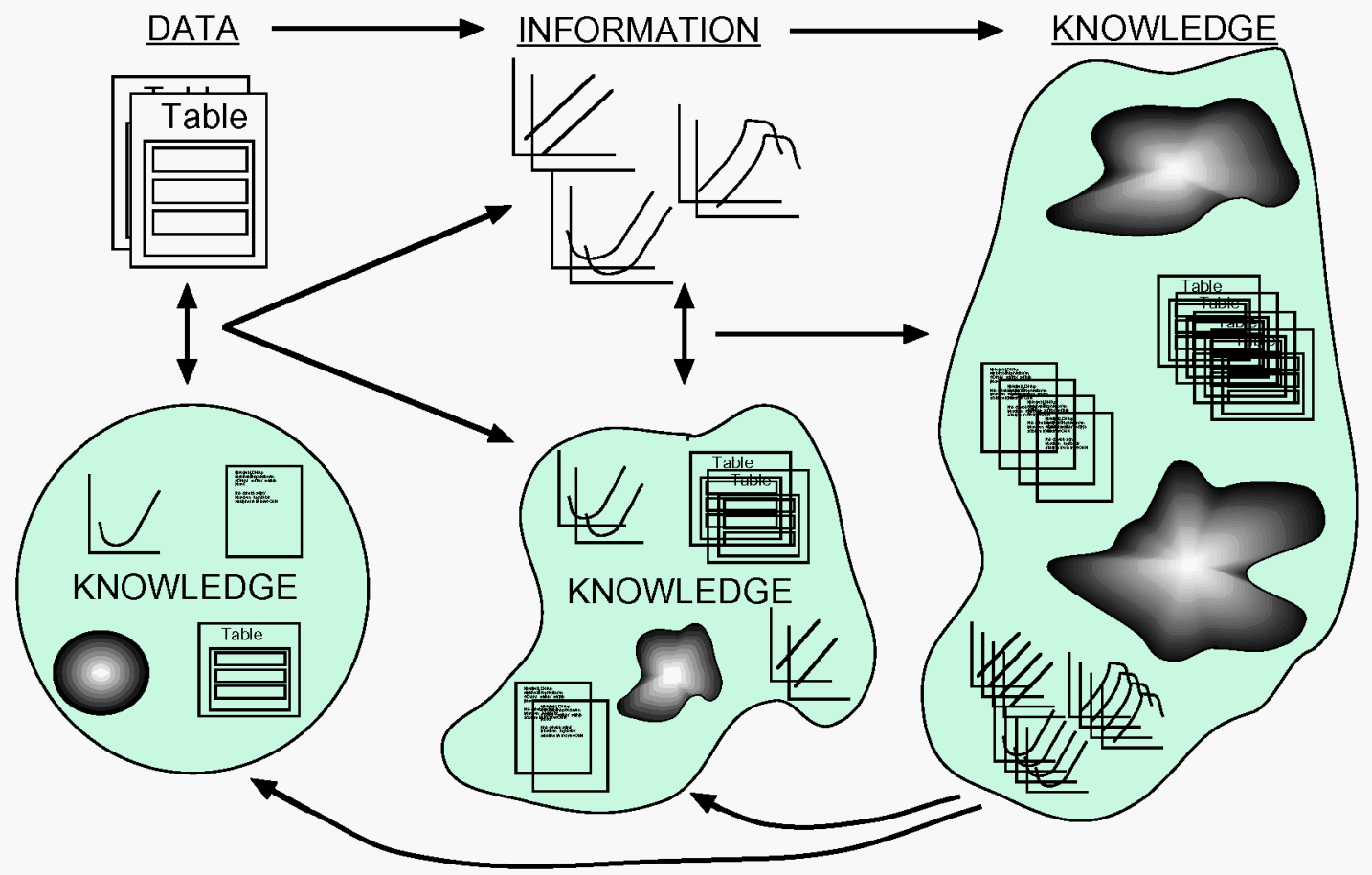

Figure 4. Sketch of the process of changing data to knowledge. 


\section{Tacit - implied but not expressed, subjective}

\section{Explicit - clearly developed meaning, objective}

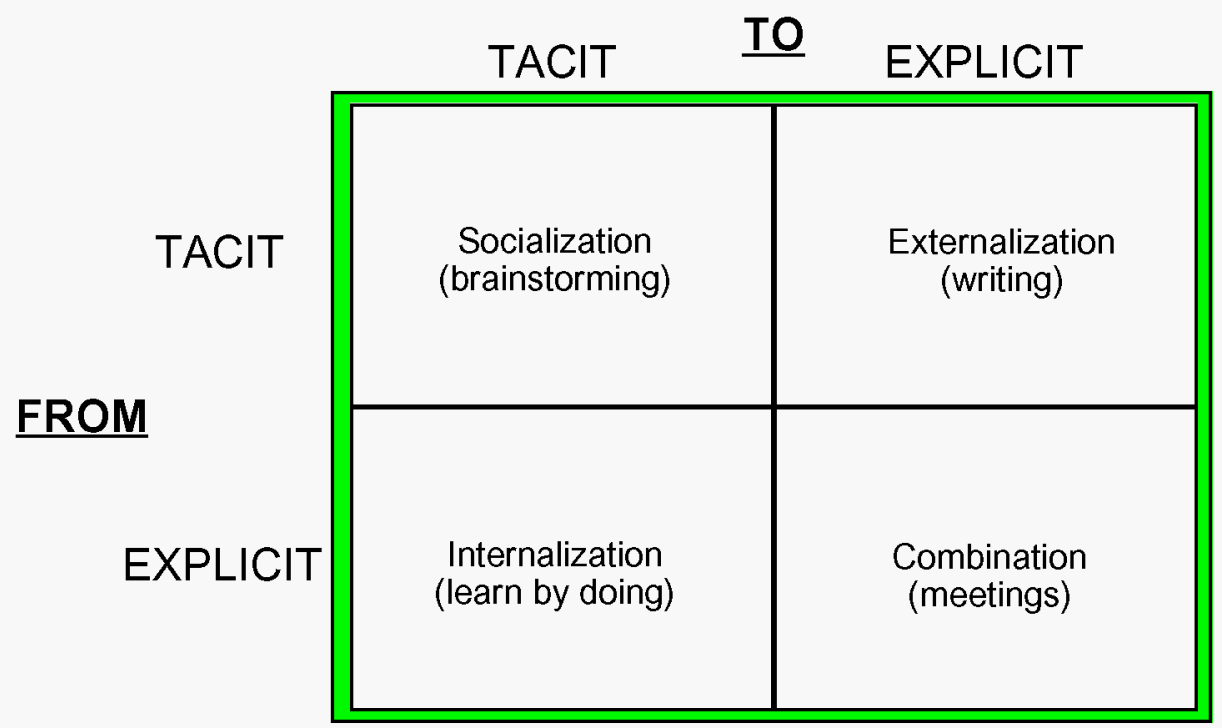

Figure 5. Four modes of knowledge creation by Nonaka 5 .

\begin{tabular}{|l|l|l|c|}
\cline { 2 - 4 } \multicolumn{1}{c|}{} & YES & MAYBE & NO \\
\hline Critical (C) Criterion = Do results look convincing/valid & $\mathrm{C}+$ & Co & C- \\
\hline Intuitive (I) Criterion = Do results look/feel right & I+ & lo & I- \\
\hline
\end{tabular}

\begin{tabular}{|c|c|c|}
\hline $\mathrm{C}+/ \mathrm{l}+$ & $\mathrm{Co} / \mathrm{l}+$ & $\mathrm{C}-/ \mathrm{I}+$ \\
\hline $\begin{array}{l}\text { Known } \\
\text { Knowledge }\end{array}$ & $\begin{array}{l}\text { Known } \\
\text { Knowledge }\end{array}$ & $\begin{array}{l}\text { Unknown } \\
\text { Knowledge }\end{array}$ \\
\hline $\mathrm{C}+/ \mathrm{lo}$ & Co/lo & C-/lo \\
\hline $\begin{array}{l}\text { Known } \\
\text { Knowledge }\end{array}$ & $\begin{array}{l}\text { Probable } \\
\text { Knowledge }\end{array}$ & $\begin{array}{l}\text { Probable } \\
\text { Knowledge }\end{array}$ \\
\hline $\mathrm{C}+/ \mathrm{l}-$ & Coll- & C-II- \\
\hline $\begin{array}{l}\text { Unknown } \\
\text { Knowledge }\end{array}$ & $\begin{array}{l}\text { Probable } \\
\text { Knowledge }\end{array}$ & $\begin{array}{l}\text { Possible } \\
\text { Knowledge }\end{array}$ \\
\hline
\end{tabular}

Figure 6. Knowledge matrix. 


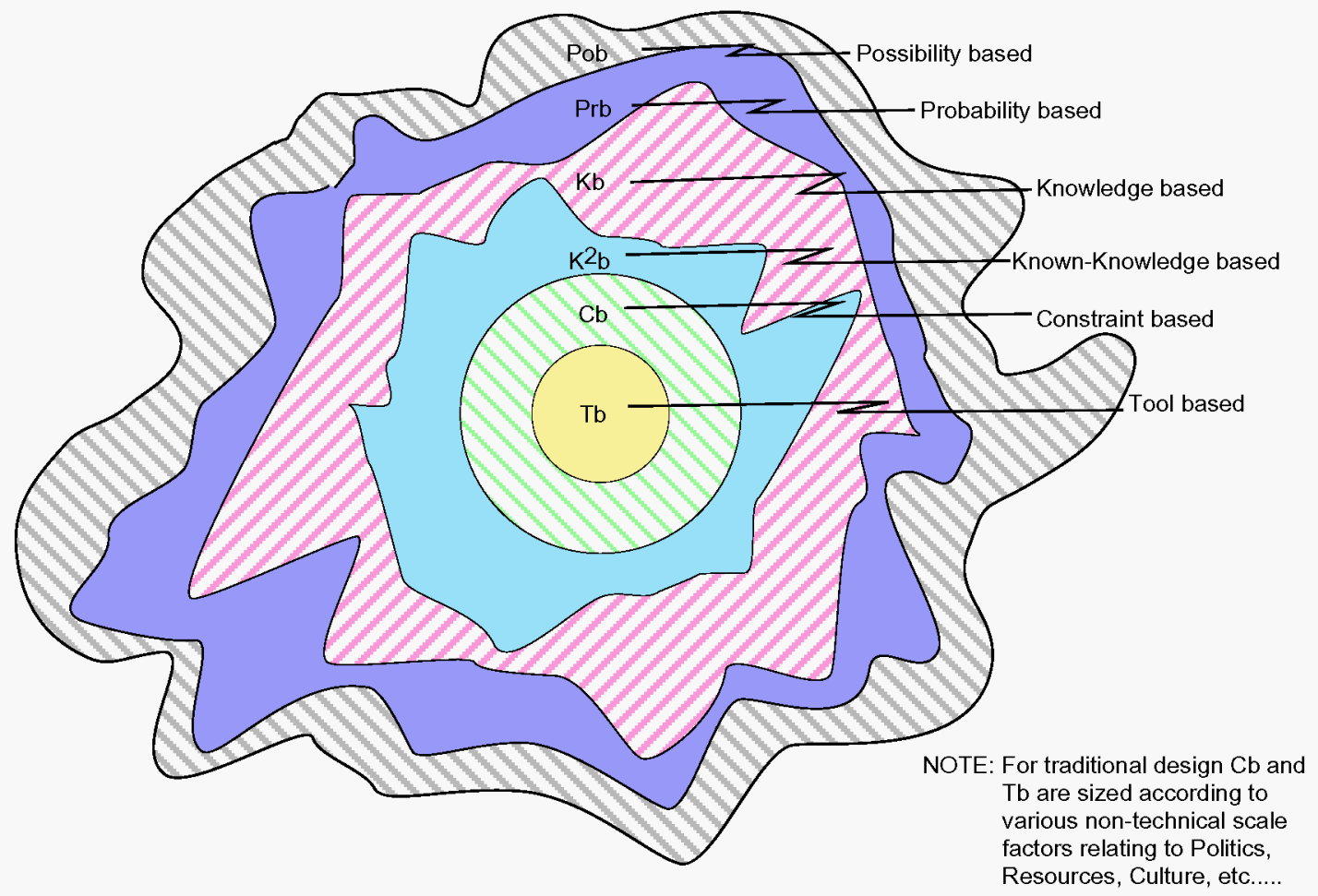

Figure 7. Sketch of design space model.

\section{Design Process}

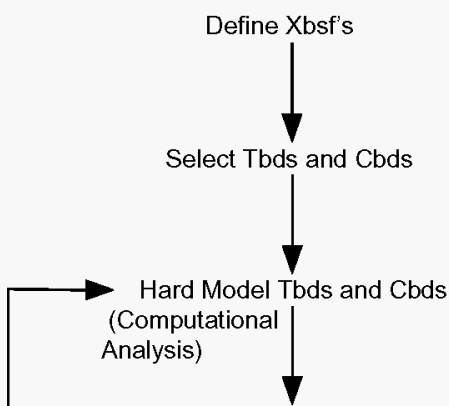

Review Output and Update Xbsf's

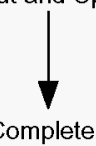

Note: Xbsf's are the scaling factors Xbds's are the design spaces

\section{Design Practice}

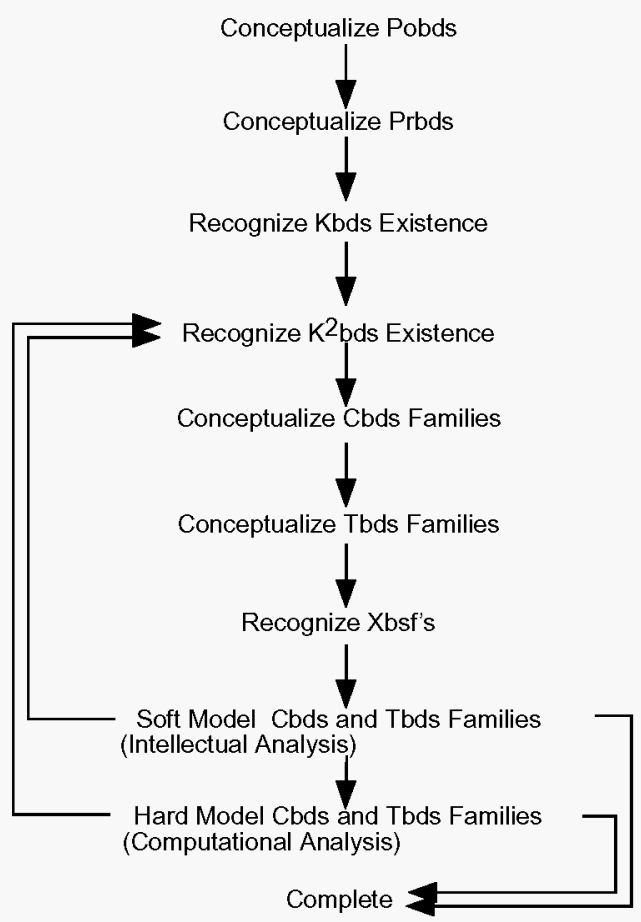

Figure 8. Sketch of design process and design practice models. 


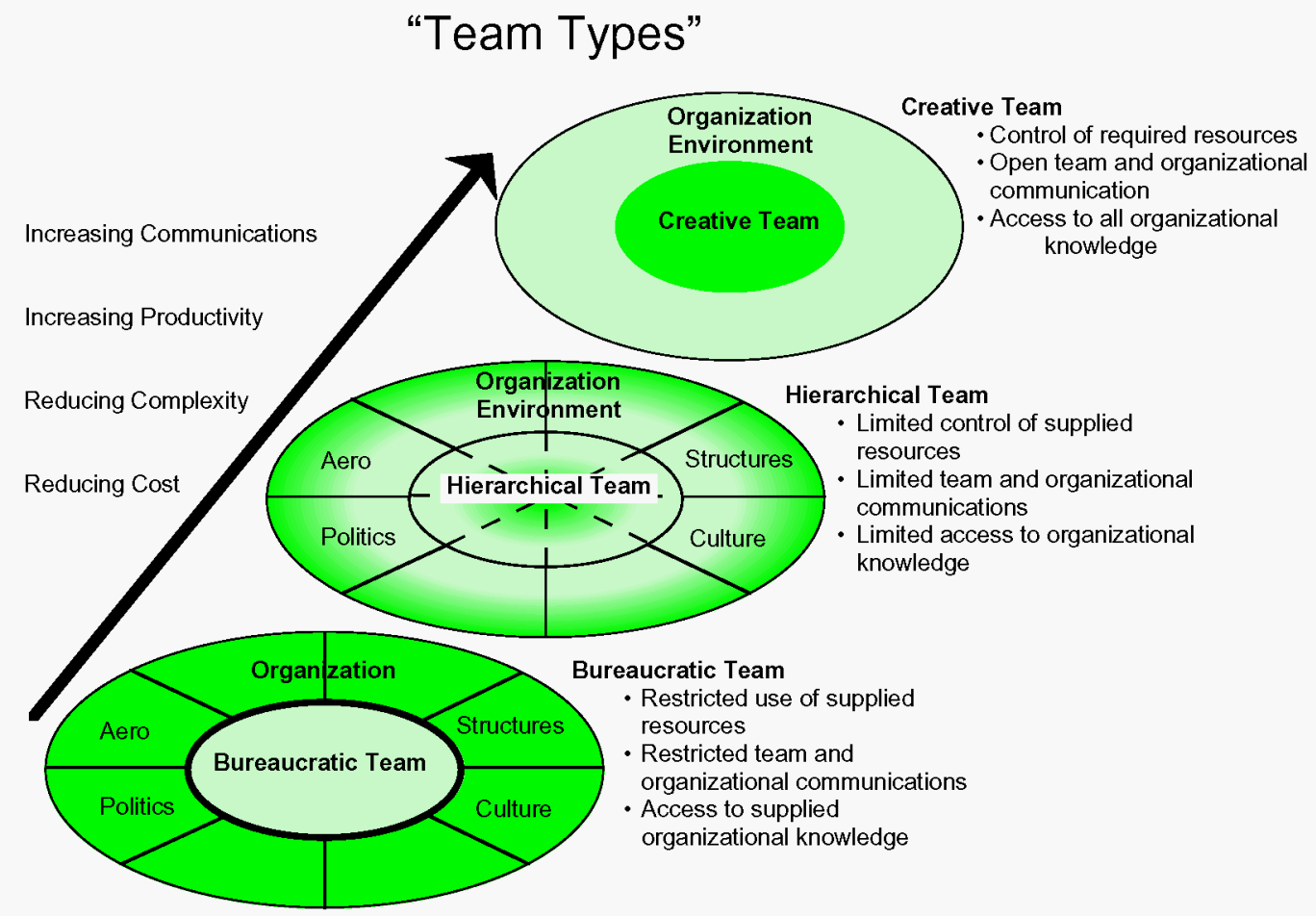

Figure 9. Sketch of team types.

\begin{tabular}{|c|l|}
\hline $\begin{array}{c}\text { Design } \\
\text { Space }\end{array}$ & \multicolumn{1}{c|}{ Description } \\
\hline $\mathrm{Pob}$ & $\begin{array}{l}\text { All 3-D shapes with smooth and continuous } \\
\text { geometry. }\end{array}$ \\
\hline $\mathrm{Prb}$ & $\begin{array}{l}\text { Pob + benign pressure loading, aerodynamic } \\
\text { insensitivity to volume changes. }\end{array}$ \\
\hline $\mathrm{Kb}$ & $\begin{array}{l}\text { Prb + drag lower than Linear Theory minimums at all } \\
\text { Mach numbers and Angle of Attack, no Aerodynamic } \\
\text { Center travel, increased volume over existing designs. }\end{array}$ \\
\hline $\mathrm{K} 2 \mathrm{~b}$ & $\begin{array}{l}\text { Kb + geometry matched to observed 3-D } \\
\text { pressure loading pattern for swept wings }\end{array}$ \\
\hline $\mathrm{Cb}$ & scale/volume required for mission \\
\hline $\mathrm{Tb}$ & analytic geometry definition capability \\
\hline
\end{tabular}

Figure 10. Description of NFW design space. 


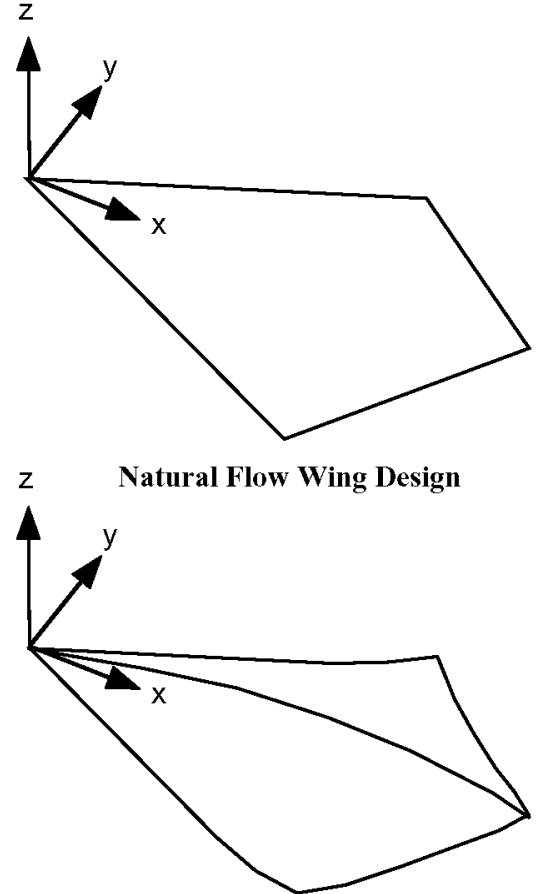

Typical Wing Design

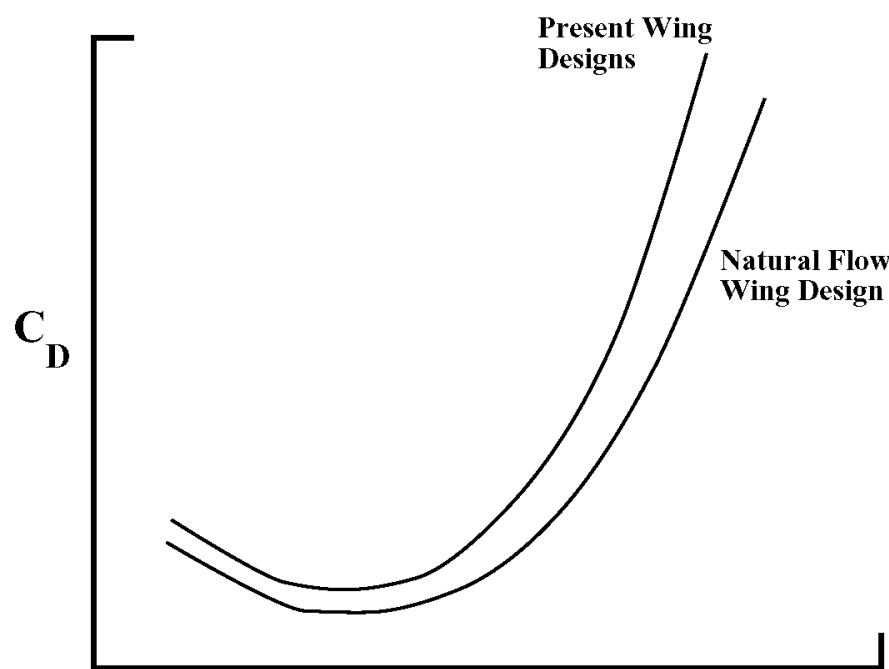

$\mathbf{C}_{\mathrm{L}}$

Figure 11. Details of the NFW design study.

\begin{tabular}{|l|l|}
\hline $\begin{array}{l}\text { Design } \\
\text { Space }\end{array}$ & \multicolumn{1}{c|}{ Description } \\
\hline Pob & $\begin{array}{l}\text { All mechanical, fluidic, pneumatic, thermal, } \\
\text { acoustic, etc. flow management and control } \\
\text { effector concepts. All vehicle planform concepts } \\
\text { comprising straight edges. }\end{array}$ \\
\hline $\mathrm{Prb}$ & $\begin{array}{l}\text { Pob + simple and lightweight. At least linear } \\
\text { lift and pitching moment up to 50 } \\
\text { attack. }\end{array}$ \\
\hline $\mathrm{Kb}$ & $\begin{array}{l}\text { Prb + a minimum of } \\
\text { aerodynamic performance and a } 50 \% \text { reduction } \\
\text { in volume requirements and weight. }\end{array}$ \\
\hline $\mathrm{K} 2 \mathrm{~b}$ & $\begin{array}{l}\text { Kb + steady-state operation. Planar } \\
\text { geometries with aligned edges. }\end{array}$ \\
\hline $\mathrm{Cb}$ & must be NEW ideas. \\
\hline $\mathrm{Tb}$ & none \\
\hline
\end{tabular}

Figure 12. Description of AACE design space. 
Technologies Developed

-In-Plane Joined Wings

- Sawtooth Forebody *

- Boundary Layer Separation Control Device *

- Passive Porosity Technology (PASSPORT) *

- Micro Drag Generators (MGD) *

- Stagnation Control Point Airfoil *

* patent pending

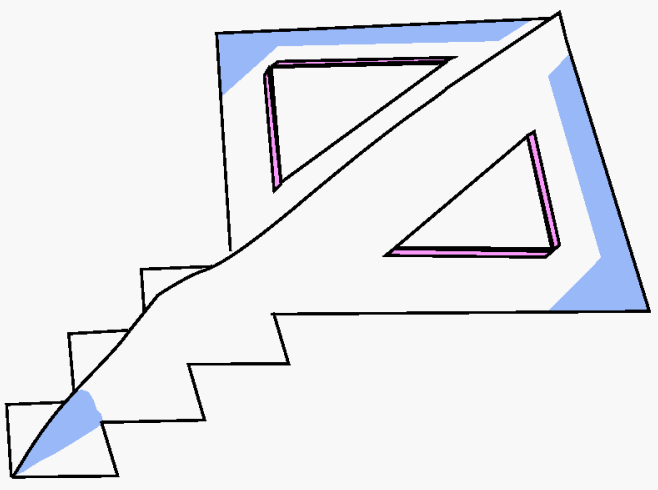

Performance Benefits

- $30 \%$ increase in maximum lift and $10 \%$ decrease in cruise drag

- Linear lift and pitching moment to $45^{\circ}$ angle-of-attack

- $20 \%$ increase in control power

- Achieved desired signature goals

- $50 \%$ reduction in control effector weight

Figure 13. Details of the AACE wing design study.

\begin{tabular}{|c|l|}
\hline $\begin{array}{c}\text { Design } \\
\text { Space }\end{array}$ & \multicolumn{1}{c|}{ Description } \\
\hline Pob & $\begin{array}{l}\text { All 3-D shapes with smooth and continuous } \\
\text { geometry defined by the existing wing planform, } \\
\text { vehicle structural volume, and engine locations. }\end{array}$ \\
\hline $\mathrm{Prb}$ & $\begin{array}{l}\text { Pob + planar edges, benign pressure } \\
\text { loading, aerodynamic insensitivity to volume } \\
\text { changes. }\end{array}$ \\
\hline $\mathrm{Kb}$ & $\begin{array}{l}\text { Prb + drag lower than Linear Theory minimums at all } \\
\text { Mach numbers and Angle of Attack, no Aerodynamic } \\
\text { Center travel, increased volume over existing designs. }\end{array}$ \\
\hline $\mathrm{K} 2 \mathrm{~b}$ & $\begin{array}{l}\text { Kb + geometry matched to observed 3-D } \\
\text { pressure loading pattern for swept wings }\end{array}$ \\
\hline $\mathrm{Cb}$ & scale/volume required for mission \\
\hline $\mathrm{Tb}$ & analytic geometry definition capability \\
\hline
\end{tabular}

Figure 14. Description of HSR design space. 

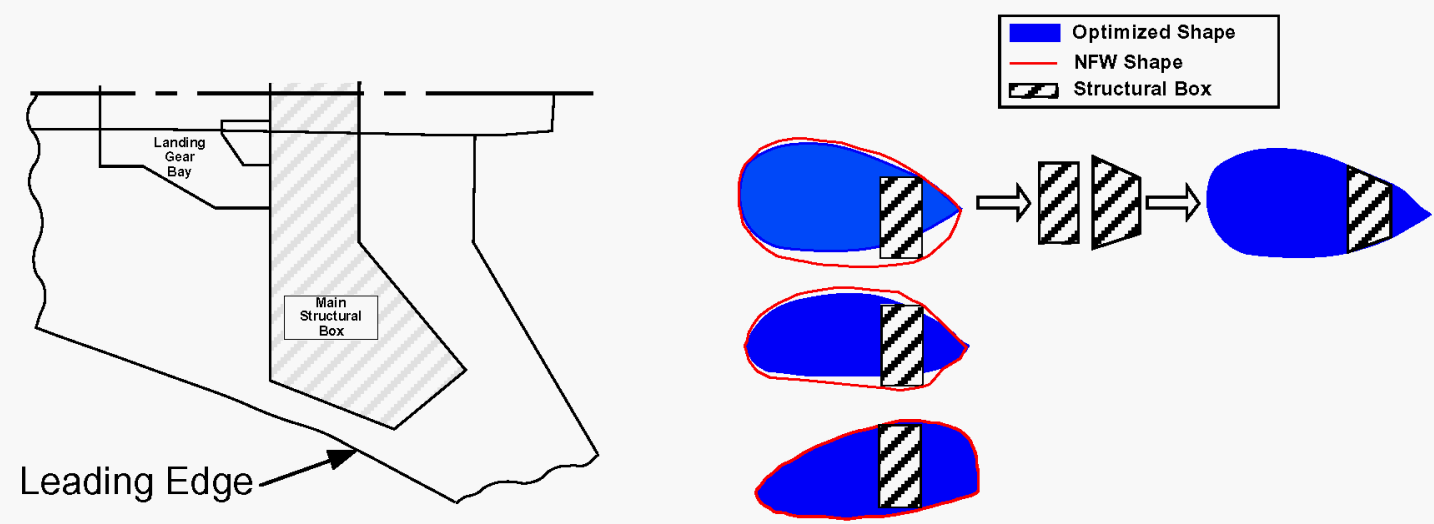

\begin{tabular}{|l|c|c|c|}
\hline Configuration & $\Delta$ Volume, $\%$ & $\Delta \mathrm{CL}_{\mathrm{L}}$ & $\Delta \mathrm{C}_{\mathrm{D}}$ \\
\hline \hline Optimized & 0.00 & 0.0 & 0.0000 \\
\hline NFW & 4.82 & 0.0 & -0.0003 \\
\hline
\end{tabular}

Figure 15. Details of HSR design study.

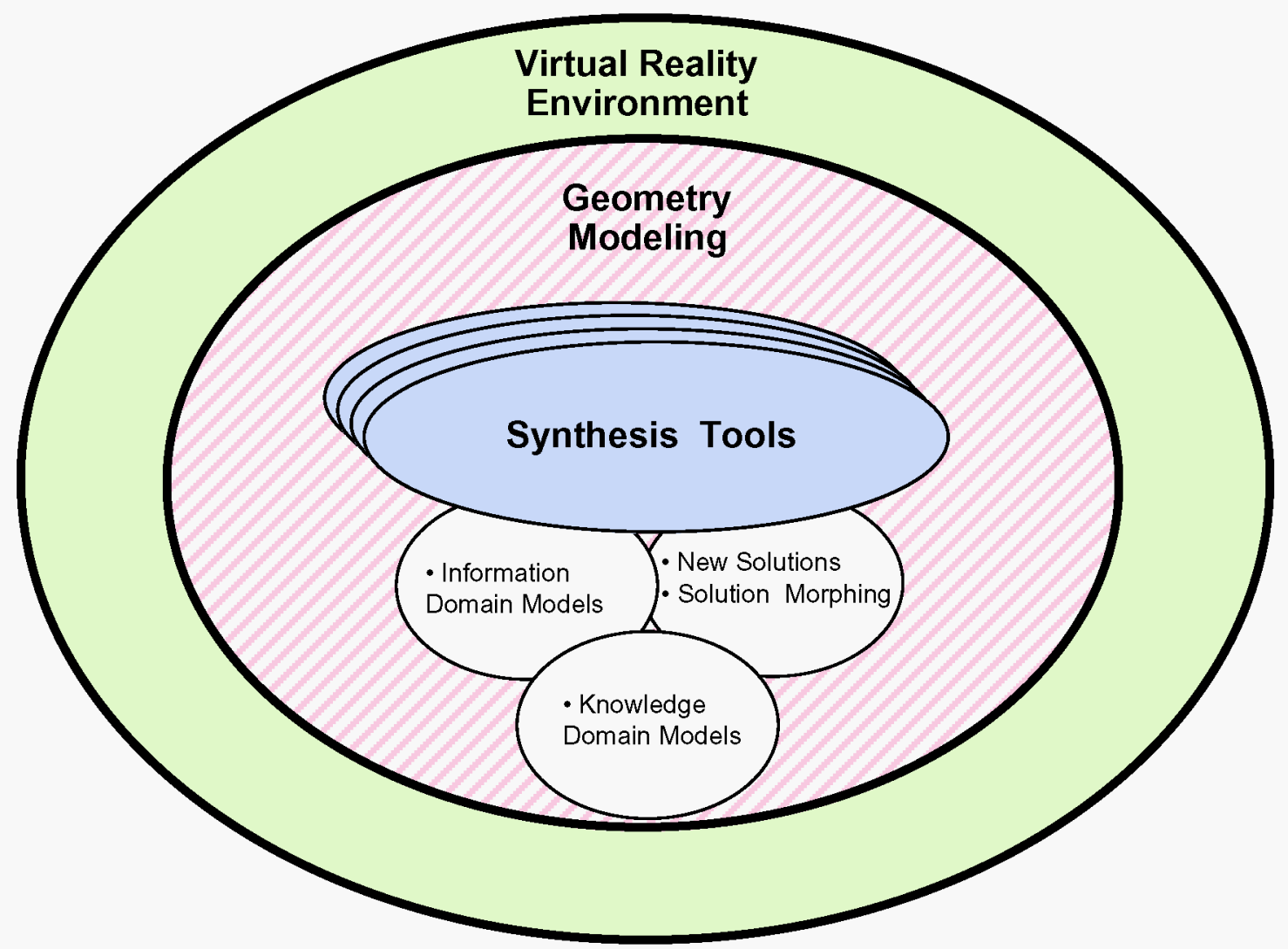

Figure 16. Sketch of virtual reality, knowledgebased design (VR KB design) model. 


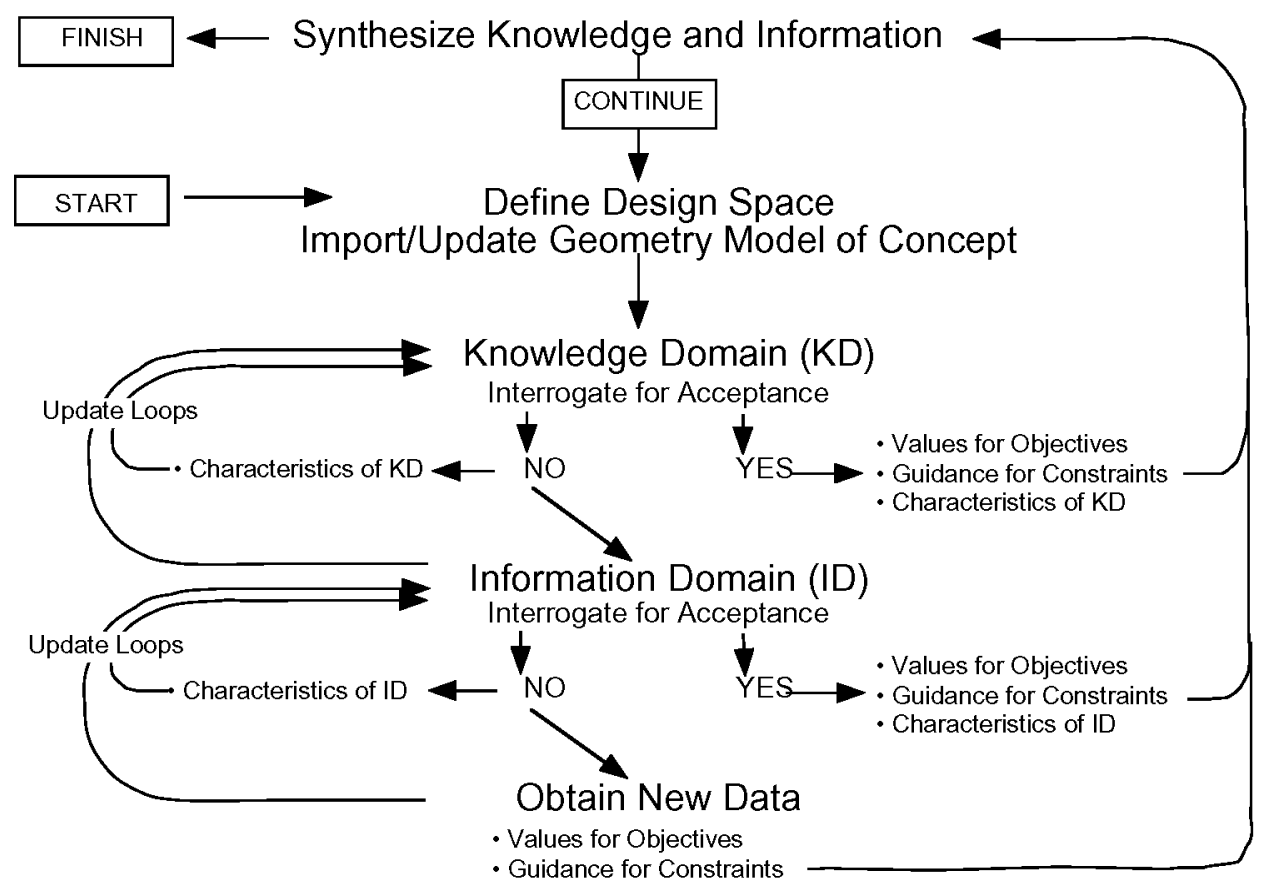

Figure 17. Sketch showing the steps of the virtual-reality, knowledgebased design system.

\section{KNOWLEDGE DOMAIN MODELS}
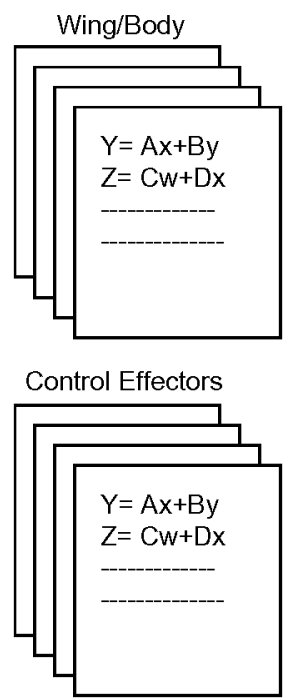
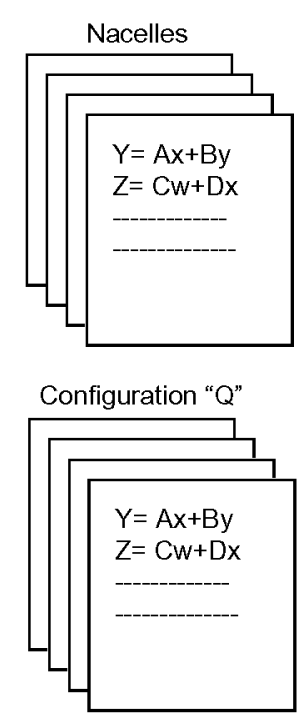

INFORMATION DOMAIN MODELS

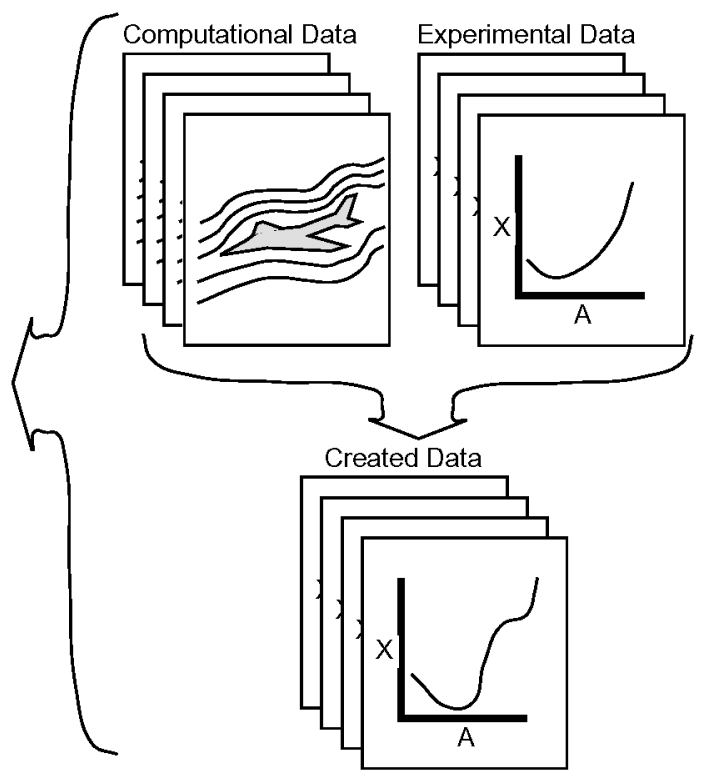

Figure 18. Sketch of knowledge and information domain models.

\section{8}




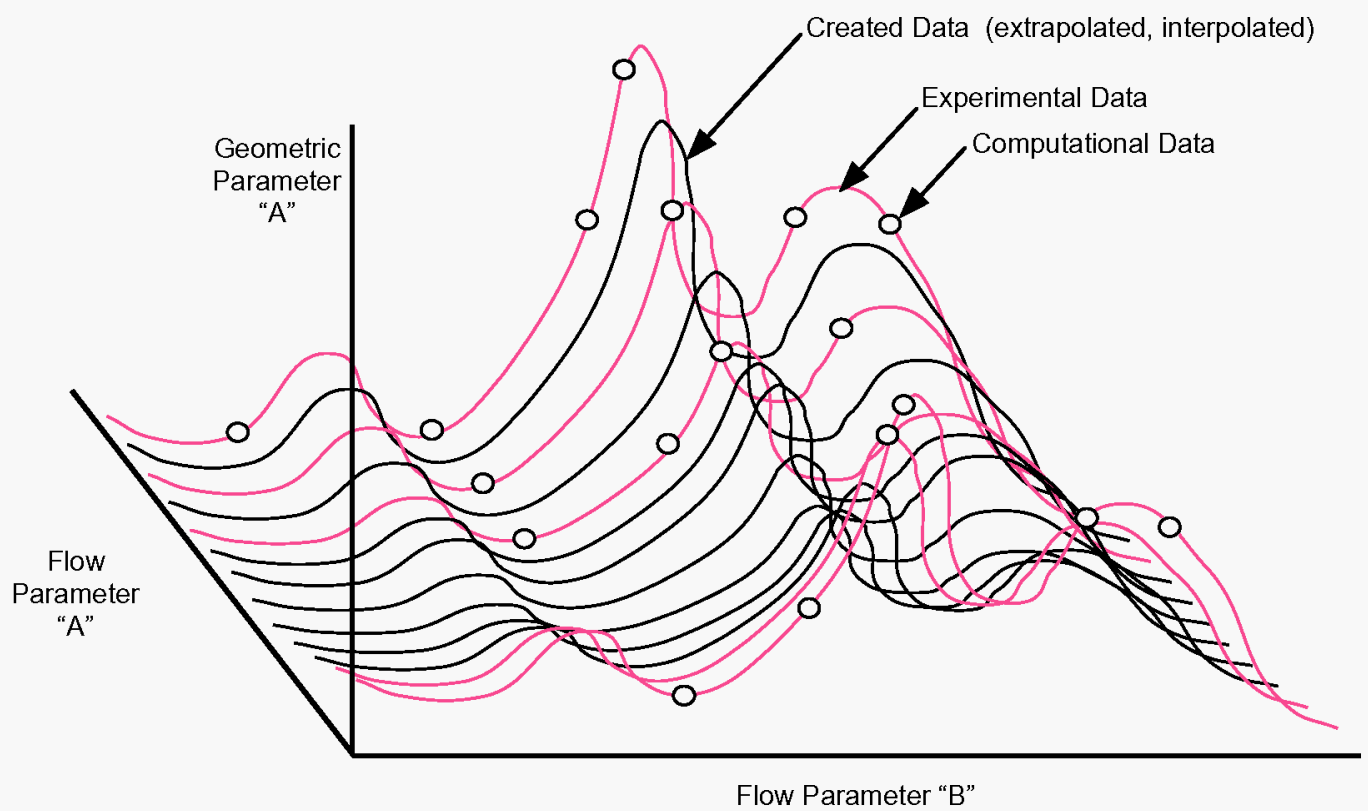

Figure 19. Representative sketch of knowledge domain model. 